\title{
An evaluation of the Technicon AutoAnalyzer for automating complement-fixation tests
}

\author{
C. E. D. TAYLOR, J. W. KERSHAW, AND G. V. HEIMER \\ From the Diagnostic Reference Laboratory, Central Public Health Laboratory, Colindale
}

SYNOPSIS Obviously there is need for a reliable means of automating complement-fixation tests. This paper offers an account of experience with an AutoAnalyzer adapted for this purpose. Results of syphilis screening tests done by the AutoAnalyzer compared with those of tests performed manually showed satisfactory agreement, the automated method being slightly less specific in our hands. There were no false negative results with the AutoAnalyzer if both Maltaner and Reiter protein antigens were used.

The current design of the AutoAnalyzer contains three major shortcomings if it is to be used for large numbers of complement-fixation tests. First and foremost is the relatively slow sampling rate compatible with adequate sample discrimination. Second is the necessity for frequently replenishing the machine with samples. Third is the need for adjusting or cleaning the flow-cell during use.

Automatic and semi-automatic methods for routine biochemical tests have been used in hospital laboratories for many years but little progress has been made towards automating tests for antibodies. There is a particular need for automating complementfixation tests, especially in the form of the Wassermann reaction. The number of sera examined annually for venereal disease in public health laboratories throughout England and Wales has almost doubled in the last ten years, having risen steadily from 232,976 in 1957 to 430,279 in 1966 (Fig. 1). In addition, the diagnosis of many viral diseases relies upon complement-fixation tests, and, if a satisfactory automated method were available, knowledge of the epidemiology of viral diseases might be greatly extended by large-scale population studies. Furthermore, in many parts of the world, especially in the developing countries, there is a great shortage of trained laboratory workers, and machines which could do large numbers of diagnostic complement-fixation tests would be especially useful (Cockburn, 1967).

Compared with most routine biochemical tests, the complement-fixation test is considerably more complicated. Moreover, the reagents required are relatively unstable, complex and notoriously capricious biological materials with appreciable batch-tobatch variation. Strict adherence to a standardized

Received for publication 3 October 1967. method is therefore essential by whatever means the test is done, and an efficient machine should be able to do tests more reliably than the most skilled manual operator.

A hand-operated machine for dispensing measured volumes of liquid into rows of wells in plastic plates and for enabling serial dilutions to be made

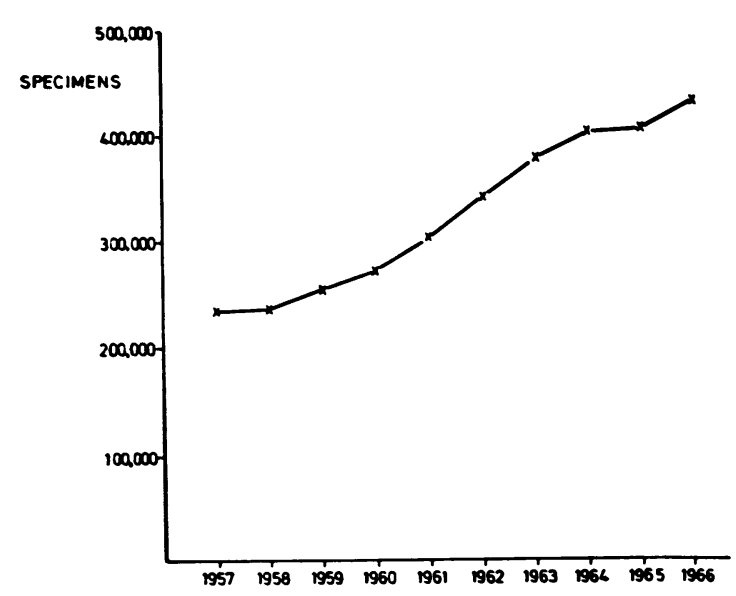

FIG. 1. Numbers of sera examined annually for venereal diseases in public health laboratories throughout England and Wales from 1957 to 1966. 
simultaneously in the wells of plastic plates has been developed ${ }^{1}$. This machine is essentially an aid for replicating certain technical manoeuvres and is not designed to carry out tests automatically from beginning to end without continuous supervision by a skilled operator.

Equipment known as the Mecolab System ${ }^{2}$, based on the principle of discrete analysis, has been designed for partially automating routine biochemical tests but requires the intermittent attention of an operator. A very large fully automated multichannel machine, the AutoChemist ${ }^{3}$, operating also on the principle of discrete analysis, has been developed for doing biochemical tests in health screening programmes and routine work in very large hospital laboratories. As far as we are aware, neither of these machines has been adapted for complement-fixation tests.

A machine now used for routine biochemical tests in many hospitals is the AutoAnalyzer ${ }^{4}$. It has been adapted for automated blood grouping and efforts to adapt it for complement-fixation tests for the diagnosis of syphilis have been described by Pugh and Gaze (1965, 1966a and 1966b). In their first report, 900 routine sera were tested using crude heart extract antigen. There were $51(5 \cdot 7 \%)$ false positive and $37(4.1 \%)$ false negative results, compared with the manual method. A further thousand sera were tested using Maltaner antigen. There was one false positive and one false negative result in this series. Sampling was carried out at a rate of 30 sera per hour. Serum controls to detect peaks caused by anticomplementary or cloudy sera were not apparently included but a pool of negative sera was used as a control in each test series. Later they described modifications to the AutoAnalyzer system and sampling rates of up to 60 sera per hour were claimed. In a further series, 250 sera were tested in the AutoAnalyzer against Reiter protein antigen. Six $(2.4 \%)$ false positive and nine $(3.6 \%)$ false negative results were obtained compared with the manual method. In a later series of 250 sera, which had been deep frozen before testing against the same antigen, no false negative but two $(0 \cdot 8 \%)$ false positive results were obtained. It was concluded that deep freezing sera before testing in the AutoAnalyzer increased the sensitivity of the test. Except in the first series, sera regarded initially as positive were tested again in the AutoAnalyzer without antigen as an anticomplementary check.

Irvine (1966) described the use of an AutoAnalyzer for the screening and titration of sera for complement-

\footnotetext{
${ }^{1}$ Shandcn Scientific Co Ltd.

2Joyce, Loebl and Co Ltd.

${ }^{3}$ AGA Medical Division, Lidingo 1, Sweden.

${ }^{4}$ Technicon Instruments Co Ltd.
}

fixing antibody to gastric (parietal) cell and thyroid $\stackrel{0}{*}$ microsomal antigens. He claimed that the automated 으 method was of equal sensitivity to the manual $\Rightarrow$ technique and had the advantage over the manual $\stackrel{\rho}{?}$ test of greater accuracy and reproducibility. His rate of sampling was 30 per hour.

The continuous flow principle of the Auto- $\frac{\bar{D}}{\bar{Q}}$ Analyzer has many attractions. A measured volume $\stackrel{\mathbb{Q}}{\Omega}$

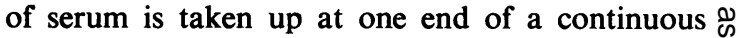
system of plastic and glass tubing through which $\overrightarrow{0}$ it is propelled by a peristaltic proportioning pump. At appropriate time intervals during its passage $\vec{\omega}$ through the system, the sample meets and mixes with predetermined amounts of reagents which are flowing continuously. The reaction temperature is usually controlled by allowing the mixture of $A$ serum sample and reagents to pass through delay if coils in a special temperature-controlled oil-bath but a series of coils in a temperature-controlled 음 water-bath offers more flexibility for experimental $\rightarrow$ purposes. The reaction mixture finally passes through a colorimeter which is connected to $a \gtrless$ pen recorder so that the result of each test is ex- $\vec{\varphi}$ pressed as a peak on a sheet of continuously moving chart paper.

We decided to explore the possibility of using an AutoAnalyzer for complement-fixation tests and to compare results with those of tests done manually on samples of the same sera.

\section{METHOD}

As a starting point, a system similar to that described by Pugh and Gaze was tried. Later, modifications were made in an attempt to increase sensitivity and to increase the sampling rate while maintaining adequate discrimination between samples. The system finally decided upon $\frac{0}{3}$ (Fig. 2) had no antigen line because we preferred to add antigen separately to each serum sample in the sample $\delta$ cup. By so doing, the reaction between antigen and antibody could be allowed to proceed at $4^{\circ} \mathrm{C}$ overnight before $ᄋ$ the addition of complement. This was found to increase the sensitivity of the test. It also resulted in considerable economy in the use of antigen, an important point if large numbers of specimens were required to be tested with $\mathcal{N}$ virus antigens which are considerably more expensive than those used for syphilis serological tests.

Complement and the sample were pumped at $0.16 \mathrm{\omega}$ $\mathrm{ml} / \mathrm{min}$ and $0.32 \mathrm{ml} / \mathrm{min}$ respectively, then mixed and segmented with air. The resulting mixture was passed through the complement-fixation stage of the system for $\frac{D}{\mathbb{D}}$ 40 minutes, after which a $5 \%$ suspension of optimally sensitized sheep red cells was added at $0.10 \mathrm{ml} / \mathrm{min}$. With further mixing, haemolysis, if appropriate, took place during the second stage which lasted 25 minutes. $\frac{\vec{D}}{\Phi}$ The total time for a sample to pass through the whole system was 65 minutes.

The way in which the complement, sample, and air are mixed is important, especially when viscous materials 


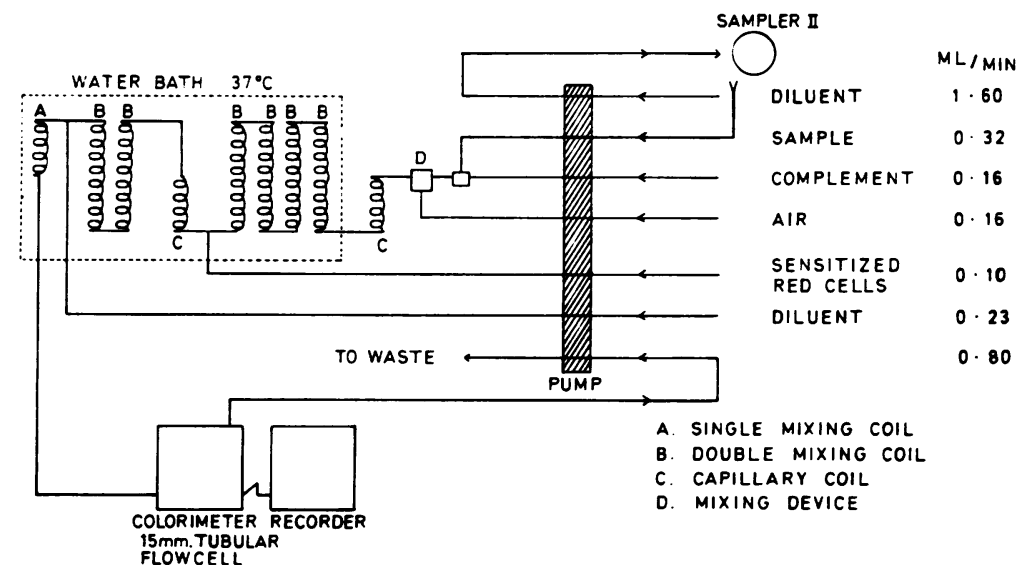
FIG. 2. Manifold and flow diagram.

FIG. 3. Red cell reservoir with glass paddles rotated by an electric motor.
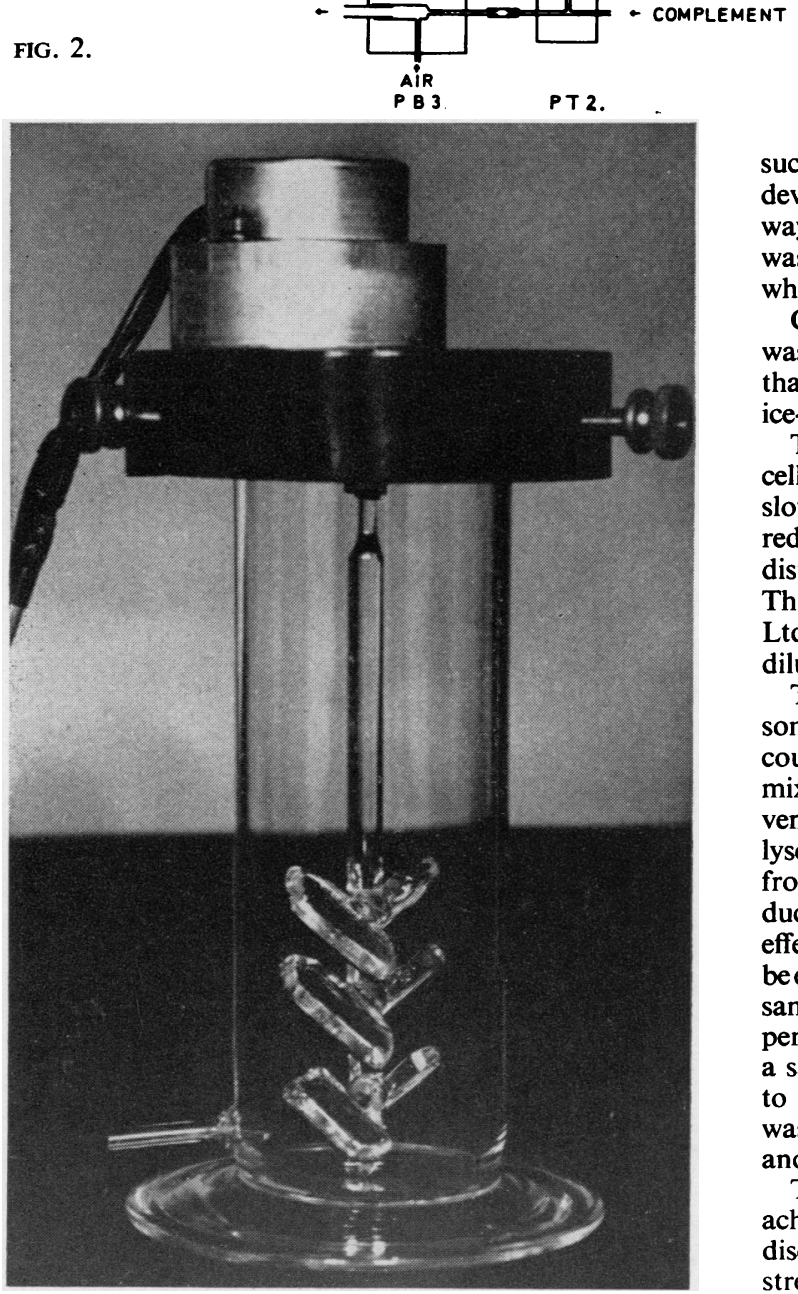

such as serum are involved. In our hands, the mixing device shown in Fig. 2 was more effective than the threeway cactus used by Pugh and Gaze; in particular, there was less tendency for samples to linger around the point where mixing took place.

Complement was diluted before use. Little deterioration was detected after periods of up to 16 hours, provided that it was kept near $0^{\circ} \mathrm{C}$ by standing its container in an ice-bath.

The reservoir holding the suspension of sensitized red cells consisted of a glass cylinder in which there were slowly rotating glass paddles designed to prevent the red cells from sedimenting and to maintain an even distribution of them throughout the suspension (Fig. 3). This reservoir (made by the Technicon Instrument Co Ltd), together with those containing complement and diluent respectively, stood in an ice-bath.

The maximum rate of sampling was determined to some extent by the efficiency with which the sample could be kept in as small a volume of the final flow mixture as possible, and the degree to which the intervening volumes of liquid could be kept free of unhaemolysed red cells. Sampling for the shortest possible time and from the largest possible tube consistent with reproducibility of sample size, enabled the maximum washing effect between samples to be obtained. This was found to be extremely important if adequate discrimination between samples were to be achieved. A cam, giving 30 samples per hour and a sample wash ratio of $1: 13$, together with a sample pump tube delivering $0 \cdot 32 \mathrm{ml} / \mathrm{min}$, were found to be the most suitable. The Technicon sample probe was replaced by a larger one of outside diameter $1.2 \mathrm{~mm}$ and inside diameter $0.85 \mathrm{~mm}$.

The maximum satisfactory rate of sampling we have achieved has been 30 samples per hour. This gave good discrimination between peaks on the recorder when the strength of complement was such that weakly positive

FIG. 3 . 
samples were discernible. Faster sampling rates resulted in loss of sensitivity as well as poor discrimination between peaks.

Haemo-sol (0.3\%) was used as a cleaning agent for the apparatus, although dilute hydrochloric acid was at times found necessary to remove protein deposits.

\section{TESTS OF SERA}

Reagents were similiar to those used in the manual test described by Bradstreet and Taylor (1962). Oxoid diluent for complement-fixation tests was used throughout.

The dilution of complement for tests was such that sera which had been found to be weakly positive by the manual method were detectable by the AutoAnalyzer. This was checked before each day's run, preferably by testing suitable dilutions of a freeze-dried pool of positive sera and ensuring that results were within acceptably reproducible limits. Similar 'standards' prepared from formalin, in dilutions of $1 / 1,000,1 / 1,250$, and $1 / 1,562$, were found to be a useful substitute for dilutions of positive serum but the response varied slightly with different batches of complement.

Horse haemolytic serum (Burroughs Wellcome \& Co Ltd) was used at a concentration of $1 / 200$, an equal volume being added to a $5 \%$ suspension of sheep red cells. A concentration greater than this tended to cause agglutination of the red cells, resulting in an irregular baseline on the recorder.

The optimum concentrations of antigens were determined by experiment on the AutoAnalyzer. Maltaner antigen (Burroughs Wellcome \& Co Ltd) was used at the concentration recommended for manual tests $(1 / 150)$ but
Reiter protein antigen (Burroughs Wellcome \& Co Ltd) was found to have an optimum concentration of $1 / 20$ by the automated method.

Each serum $(0.1 \mathrm{ml})$ was tested with and without antigen $(0.1 \mathrm{ml})$ present, in two consecutive sample cups, the effective rate of analysis therefore being 15 sera per hour. In the second sample cup of each pair, antigen was replaced by diluent and the reaction in this cup acted as a serum control. A positive result was indicated by a difference in the recorded peak-height between the test and control samples of more than 0.01 on the optical density scale.

Only by allowing the antigen-antibody reaction to take place overnight at $4^{\circ} \mathrm{C}$ could very weakly positive serum samples be detected.

\section{RESULTS}

A preliminary series of tests was carried out, using Maltaner antigen, on sera routinely submitted for the Wassermann reaction and kindly supplied by Professor R. E. O. Williams of St Mary's Hospital, London. Results obtained with the AutoAnalyzer agreed with those of tests done manually at St Mary's Hospital in 56/58 samples, 41 being positive and 17 negative. One was positive with the AutoAnalyzer but negative by the manual test, and one was negative with the AutoAnalyzer but positive by the manual test.

A further series of tests was carried out on 90 sera kindly supplied by Dr A. E. Wilkinson, Director of the Venereal Diseases Reference Laboratory at
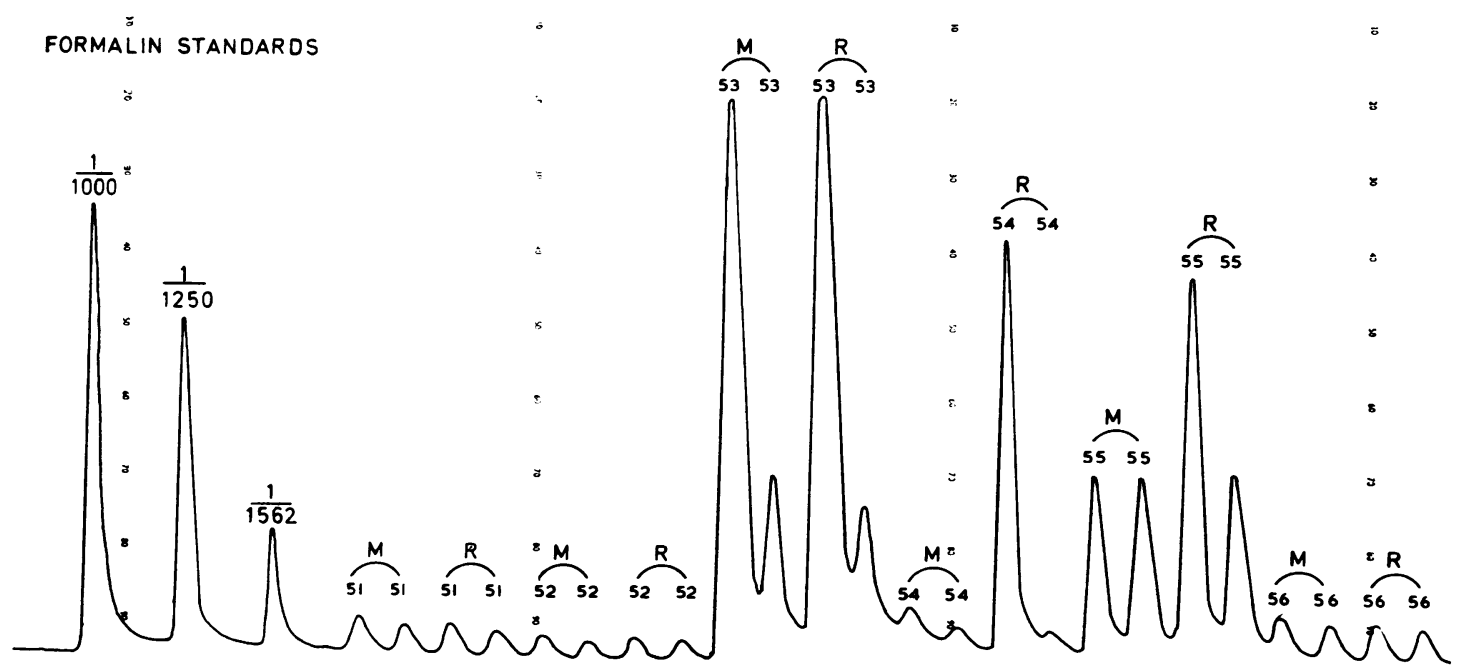

FIG. 4. Example of recording with routine specimens. Formalin dilutions act as positive serum controls. $M=$ Maltaner antigen $\quad R=$ Reiter protein antigen 
the London Hospital. The sera in this second series were chosen so that they would constitute an especially rigorous test for the AutoAnalyzer. Approximately half of them had been found to be positive in one or more of three manual tests: (1) Reiter protein CFT, (2) cardiolipin Wassermann reaction, and (3) VDRL slide test. By choosing a series in which half of the sera had been found positive and half had been found negative in manual tests, discrepancies between results obtained by the AutoAnalyzer and those obtained manually were most readily apparent. The sera were tested by the AutoAnalyzer in three approximately equal batches being placed in random order within the batches. Each serum was tested by the AutoAnalyzer against Reiter protein and Maltaner antigens, with a serum control cup following each antigen cup (Fig. 4). Results for the Reiter protein antigen are shown in Table I. No serum, negative by the AutoAnalyzer, was positive by the manual test. Six $(6.7 \%)$

TABLE I

COMPARISON OF RESULTS USING REITER PROTEIN ANTIGEN

Manual Method

Automated Method Done at the

Done at the

Diagnostic Reference Laboratory

Venereal Diseases

Reference Laboratory

\begin{tabular}{lrccc}
\hline & Negative & $\begin{array}{c}\text { Weakly } \\
\text { Positive }\end{array}$ & $\begin{array}{c}\text { Strongly } \\
\text { Positive }\end{array}$ & Total \\
\cline { 2 - 5 } & 43 & 6 & 0 & 49 \\
Negative & 0 & 9 & 9 & 18 \\
Weakly positive & 0 & 5 & 18 & 23 \\
Strongly positive & 43 & 20 & 27 & 90
\end{tabular}

sera negative by the manual test were weakly positive by the AutoAnalyzer. Results of the cardiolipin (Maltaner) Wassermann reaction are shown in Table II. Four $(4 \cdot 4 \%)$ sera positive by the manual method were negative by the AutoAnalyzer, and six $(6.7 \%)$ negative by the manual method were weakly positive by the AutoAnalyzer.

TABLE II

COMPARISON OF RESULTS USING CARDIOLIPIN (MALTANER) ANTIGEN

\begin{tabular}{|c|c|c|c|c|}
\hline \multirow{2}{*}{$\begin{array}{l}\text { Manual Method } \\
\text { Done at the } \\
\text { Venereal Diseases } \\
\text { Reference Laboratory }\end{array}$} & \multicolumn{4}{|c|}{$\begin{array}{l}\text { Automated Method Done at the } \\
\text { Diagnostic Reference Laboratory }\end{array}$} \\
\hline & Negative & $\begin{array}{l}\text { Weakly } \\
\text { Positive }\end{array}$ & $\begin{array}{l}\text { Strongly } \\
\text { Positive }\end{array}$ & Total \\
\hline $\begin{array}{l}\text { Negative } \\
\text { Weakly positive } \\
\text { Strongly positive } \\
\text { Total }\end{array}$ & $\begin{array}{r}50 \\
4 \\
0 \\
54\end{array}$ & $\begin{array}{r}6 \\
1 \\
3 \\
10\end{array}$ & $\begin{array}{r}0 \\
5 \\
21 \\
26\end{array}$ & $\begin{array}{l}56 \\
10 \\
24 \\
90\end{array}$ \\
\hline
\end{tabular}

DISCUSSION

It would seem that, using both Maltaner and Reiter protein antigens, the AutoAnalyzer would be sufficiently reliable for syphilis screening tests, although any serum giving a positive result would need to be referred for further tests. A small proportion of false positive results compared with the manual method would be tolerable because it is essential for safety's sake that an automated method used for screening purposes should not be less sensitive than the manual technique. However, there are at present three main limitations to using the AutoAnalyzer for screening large numbers of sera. First is the relatively slow sampling rate of only 15 sera per hour, necessary to achieve adequate discrimination between samples. The second is concerned with the fact that the sample tray has only 40 places and therefore has to be changed manually every 1 hour 20 minutes. If the AutoAnalyzer could be fitted with a continuous feed from a refrigerated sample store, so that it could be left to work unattended for say 20 out of 24 hours, then an effective sampling rate of 15 sera per hour, ie 300 per 24-hour period, might be acceptable as an economic and practical procedure for routine screening. With this idea in mind, we ran the apparatus successfully on one occasion for 16 hours without attention. One per cent formalin solution (which effectively simulates positive serum) was sampled from cups in the sample plate which was allowed to revolve continuously throughout the experiment. Complement diluted $1 / 38$ showed only slightly detectable deterioration during this period and gave similar readings with 'standards' prepared from a pool of freeze-dried Wassermann reaction positive sera at the beginning and the end of the experiment. Decomposition products did not accumulate in the flow-cell to any appreciable extent. However, several attempts to test serum samples over such a prolonged period were unsuccessful because of the third problem which is that the continuous running of serum samples with a sufficiently sensitive concentration of complement deposited organic material on the walls of the flow-cell. This required occasional adjustment of the 100 per cent transmission control and even cleaning of the cell.

We carried out three experiments to try to define the features limiting the rate of sampling.

1 A suspension of red cells, of the same strength as that which passes through the colorimeter when a serum sample is positive, was placed in several sample cups and the sampler connected straight to the colorimeter. The tracing on the recorder was similar to that produced by positive serum samples passing through the whole system as set up for complement fixation tests.

2 The length of the system was shortened and, to compensate for the loss of reaction time thereby 
incurred, the temperature of the water-bath was raised above $37^{\circ} \mathrm{C}$. At $45^{\circ} \mathrm{C}$, a fixation time of 13 minutes in one coil, and haemolysis time of six minutes in a half coil, gave no better discrimination between samples.

3 Parts of the system, including the glass mixing and delay coils, were replaced by continuous lengths of polythene tubing wound at appropriate intervals into coils of dimensions similar to the glass ones, thus giving a system of relatively nonwettable materials and with few joints. However, no improvement in the separation of samples was achieved.

From these experiments, it appears that sample discrimination is not significantly affected by the total length of plastic and glass tubing in the whole system, but that the main feature limiting the rate of sampling is the time required to wash out the colorimeter flow-cell after each sample. If the speed of sampling is increased to more than $\mathbf{3 0}$ samples per hour, there is insufficient time to allow complete washing of the flow-cell before the next sample arrives, and the recorder pen fails to return to the haemolysis baseline, resulting in an escalation effect on the recording and making it very difficult to discriminate between samples. This problem seems to be inherent in a continuous flow system but might conceivably be overcome by the use of an alternative colorimeter.
In forming a judgement about the suitability of the AutoAnalyzer for complement-fixation tests, 으 we conclude that, although this machine could probably be used reliably for syphilis screening $\stackrel{\vec{\rho}}{\rightarrow}$ tests, the present maximum sampling rate, the 0 necessity for frequent manual feeding of samplings and the need for relatively frequent adjustments to or cleaning of the flow-cell, all defeat the main $\stackrel{\square}{\triangle}$ object of an automated process, rendering it un- ® economical for routine testing of large numbers of sera.

We are most grateful for help received throughout this study from Dr O. M. Lidwell and his staff at Colindale. 옹 We thank also Professor R. E. O. Williams, St Mary's Hospital, Paddington, and Dr A. E. Wilkinson, Venereal Diseases Reference Laboratory, London Hospital is Research Laboratories, Whitechapel, for providing of serum samples and for making results of their tests available to us; also Mr Ronald Jay of the Technicon 은 Instrument Co Ltd for assistance with the AutoAnalyzer. -

This work was made possible by a grant from the Ministry of Health.

\section{REFERENCES}

Bradstreet, C. M. P., and Taylor, C. E. D. (1962). Mth. Bull. Minist Hlth Lab. Serv., 21, 96.

Cockburn, W. C. (1967). Personal communication.

Irvine, W. J. (1966). Clin. exp. Immunol., 1, 341.

Pugh, V. W., and Gaze, R. W. T. (1965). Brit. J. vener. Dis., 41, 221. (1966a). J. med. Lab. Technol., 23, 126.

_-, - (1966b). J. clin. Path., 19, 595. 